\title{
Association of the p53 codon 72 polymorphism with breast cancer in central part of Iran
}

\author{
Hojjat Rouhi Boroujeni ${ }^{1}$, Mehrdad Karimi ${ }^{2 \star}$, Saadat Moshkelani ${ }^{3}$ and Pouya Parsaei ${ }^{3}$ \\ ${ }^{1}$ Department of Pharmacology, Shahrekord University of Medical Sciences, Shahrekord, Iran. \\ ${ }^{2}$ Department of Surgery, Shahrekord University of Medical Sciences, Shahrekord, Iran. \\ ${ }^{3}$ Young Researchers Club, Shahrekord Branch, Islamic Azad University, Shahrekord, Iran..
}

Accepted 10 August, 2012

\begin{abstract}
The tumor suppressor gene protein 53 (p53) plays a general role in cell cycle control, the initiation of apoptosis and in DNA repair. The human p53 gene is mutated and accumulated in more than $50 \%$ of cancers. Codon 72 exon 4 polymorphism (Arg72Pro) of the p53 gene has been implicated in cancer risk. This study was aimed at investigating the possible association between p53 Arg72Pro polymorphism and susceptibility to breast cancer among Iranian population. The p53 Arg72Pro genotypes were determined by polymerase chain reaction - restriction fragment length polymorphism (PCR-RFLP) analysis in 135 breast cancer cases and 150 controls. The PCR products were digested with BstU I restriction enzyme and the DNA fragments were then resolved by electrophoresis in $2 \%$ agarose gel. Out of the 135 breast cancer samples, 102 (75.55 \%) samples were heterozygous (Arg/Pro), 27 (20\%) samples homozygous for arginine (Arg/Arg) and 6 (4.45\%) samples homozygous for proline (Pro/Pro). The frequencies of the three p53 genotypes; Arg/Pro, Arg/Arg and Pro/Pro in controls were 62, 24 and $14 \%$, respectively. Heterozygosity for Arg/Pro of p53 codon 72 is potentially one of the genetic risk factors for breast cancer. The p53 Arg72Pro polymorphism may be used as a stratification marker in screening individuals at a high risk of breast cancer.
\end{abstract}

Key words: Breast cancer, protein 53 (p53), polymorphism, codon 72.

\section{INTRODUCTION}

Breast cancer is the most frequently encountered cancer in women throughout the world. Epidemiologic studies have suggested a number of risk factors, including genetic and environmental ones. The protein 53 (p53) tumor suppressor gene is the most involved genetic factor for breast cancer (Mabrouk et al., 2003). The gene for the tumor suppressor protein p53 occupies a central role in mediating cellular responses to DNA damage. Its activation results in either growth arrest in the G1 phase of the cell cycle or in apoptosis. The p53 gene contains a variety of polymorphisms and mutations (Zur Hausen, 2002; Aoki et al., 2009). Mutations in the p53 gene are associated with more than $50 \%$ of human cancers, and

*Corresponding author. E-mail: moshkelanii@yahoo.com. Tel: +989132080314.
$90 \%$ of them affect p53-DNA interactions, and result in a partial or complete loss of transactivation functions (Zubo et al., 2009).

The p53 tumor suppressor gene, located on chromosome $17 \mathrm{p} 13$, is one of the most commonly mutated genes in all types of human cancer ( $\mathrm{He}$ et al., 2011; Chen et al., 2008). The p53 tumor suppressor gene is frequently mutated in many forms of human carcinomas. A common polymorphism occurs at codon 72 of exon 4, with two alleles encoding either arginine (CGC) or proline (CCC). This p53 polymorphism is reportedly associated with cancer susceptibility. The distribution of the three genotypes (Arg/Arg, Arg/Pro and Pro/Pro) depends largely on the ethnic composition of the studied population (Omori et al., 2004). Recent studies showed the relation between p53 gene polymorphism with cancer of the stomach (Takeda et al., 2000), lung (Özbey et al., 2011), breast (Pich et al., 2000), ovary 


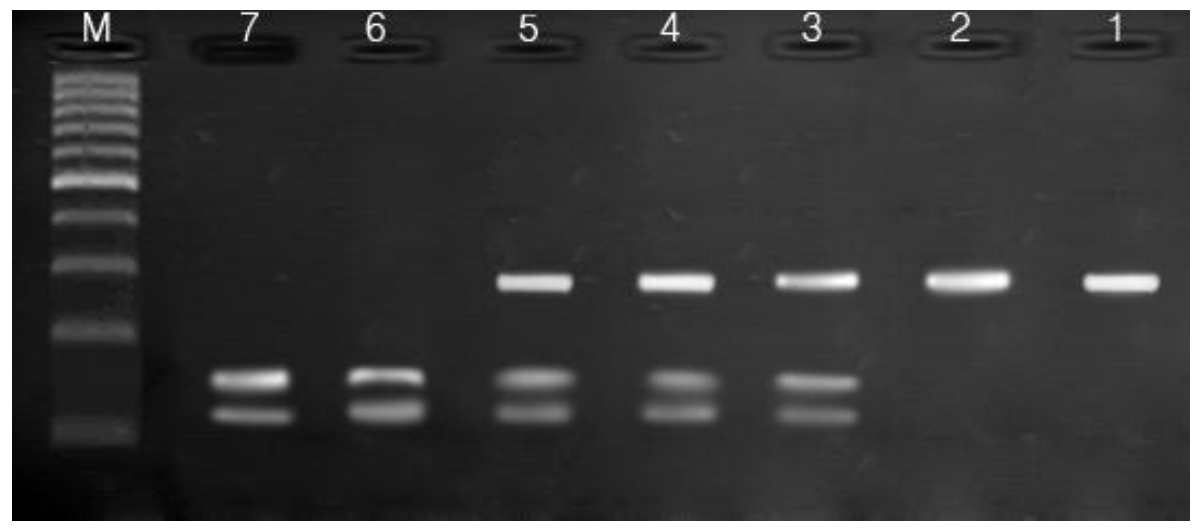

Figure 1. Genotype analysis by digestion of the amplified product and RFLP; lanes 1 and 2 are homozygote samples for Arg allele, lanes 3-4 are Arg/Pro heterozygote and lanes 6 and 7 are Pro homozygote samples. Lane M, 100 bp DNA ladder (Fermentas).

(Agorastos et al., 2004) and cervix (Jiang et al., 2010) among others in different parts of the world. In the present study, we examined the relation between the codon 72 polymorphism in p53 and the risk for breast tumorigenesis in Iranian patients.

\section{MATERIALS AND METHODS}

\section{Sample collection and DNA extraction}

Genomic DNA was purified from blood samples of 135 cases of breast cancer and 150 controls by DNA extraction kit according to the manufacturer's instructions. Samples were recruited from different hospitals of Isfahan (central part of Iran) during the period from February 2010 - October 2011. The isolated DNA was quantified by the agarose gel.

Primer, polymerase chain reaction (PCR) assay and restriction fragment length polymorphism (RFLP) analysis

PCR amplification was performed with two sets of primers: the outer oligonucleotide primers (forward: 5'-GCT CTT TTC ACC CAT CTA CAG -3'; reverse: 5'-TGA AGT CTC ATG GAA GCC AGC-3') and the inner oligonucleotide primers (forward: 5'-TCC CCC TTG CCG TCC CAA- 3'; reverse: 5'-CGT GCA AGT CAC AGA CTT-3') (Doosti et al., 2011).

The target sequence was amplified in a $50 \mu \mathrm{L}$ reaction volume containing of genomic DNA, $0.2 \mathrm{mM}$ dNTPs, $1 \mathrm{X}$ Taq buffer, $2 \mathrm{mM}$ $\mathrm{MgCl}_{2}, 100 \mathrm{ng}$ of each primer, and 1 unit of Taq DNA polymerase (Fermentas, Germany). The first round of PCR was carried out by applying a step-up program as follows: initial denaturation for $5 \mathrm{~min}$ at $94^{\circ} \mathrm{C}$, followed by 30 cycles of $94^{\circ} \mathrm{C}$ for $1 \mathrm{~min}, 58^{\circ} \mathrm{C}$ for $1 \mathrm{~min}$, and $72^{\circ} \mathrm{C}$ for $1 \mathrm{~min}$, with a final extension for $5 \mathrm{~min}$ at $72^{\circ} \mathrm{C}$. Two to $5 \mu \mathrm{L}$ from the first round amplicon was used as a template for the second round PCR with the identical PCR program by inner oligonucleotide primers.

The BstU I restriction enzyme cuts within the sequence corresponding to the arginine codon (CGC) at position 72 to generate two visible fragments of 160 and $119 \mathrm{bp}$, leaving the proline allele uncut. A $20-\mu \mathrm{L}$ of PCR product was digested overnight at $37^{\circ} \mathrm{C}$ in a $25 \mu \mathrm{L}$ reaction volume containing 5 units of BstU I (Fermentas, Germany). After overnight digestion, the fragments were separated by electrophoresis on a $2 \%$ agarose gel and stained with ethidium bromide. Logistic regression analyses were used to adjust for possible confounding variables, and data were evaluated using the Pearson $X^{2}$ tests.

\section{RESULTS}

Genotyping of the p53 codon 72 polymorphism was successful in 135 of 142 (95.07\%) breast cancer cases and 150 of $158(94.93 \%)$ controls. Codon 72 arginine and proline alleles were investigated by PCR-based digestion analysis. The recognition site (CGCG) of the restriction enzyme was present only in the arginineencoding allele. Thus, the proline allele is identified by the presence of a single fragment of $279 \mathrm{bp}$, and the arginine allele by two fragments of 160 and $119 \mathrm{bp}$, respectively. Heterozygous samples displayed all three fragments (Figure 1).

The frequency of the two alleles in breast cancer patients was compared with the frequency in the healthy control subjects. A significant difference in the genotype distribution was observed between the controls and patients with breast cancer. The distribution of the Arg/Arg, Arg/Pro and Pro/Pro genotypes in the control group was 36, 93 and 21 respectively. Allele frequencies in the control group were 0.55 for the Arg allele and 0.45 for the Pro allele. Among the patients, the frequencies of the Arg and Pro allele were 0.57 and 0.43 respectively. The corresponding distribution of the Arg/Arg, Arg/Pro and Pro/Pro genotypes in the patients was 27, 102 and 6, respectively (Table 1 ).

Our results indicate that individual heterozygous for the Arg allele has a higher risk of developing breast cancer than homozygotes and proline- homozygotes. A comparison of the genotype frequencies between breast cancer patients and normal controls confirmed the accumulation of Arg/Pro genotype in these patients $(\mathrm{P}<0.01)$. 
Table 1. Genotype and allele frequencies of p53 in patients with breast cancer and controls.

\begin{tabular}{lccc}
\hline Codon 72 genotypes & Breast cancer $(\mathbf{n}=\mathbf{9 5 . 0 7 \% )}$ & Controls $(\mathbf{n}=\mathbf{9 4 . 9 3} \%)$ & $\boldsymbol{P}$-value \\
\hline Arg/Arg & $27(20)$ & $36(24)$ & $<0.01$ \\
Arg/Pro & $102(75.55)$ & $93(62)$ & $<0.02$ \\
Pro/Pro & $6(4.45)$ & $21(14)$ & $>0.005$ \\
Arg Alleles & 57 & 55 & $>0.10$ \\
Pro Alleles & 43 & 45 & $<0.05$ \\
\hline
\end{tabular}

\section{DISCUSSION}

Although several studies have attempted to establish an eventual association between the polymorphism at codon 72 and human carcinogenesis, the issue is still a matter of controversy. Interestingly, a polymorphism has been demonstrated at codon 72 , where the proline is frequently replaced by an arginine. Both forms are morphologically wild-type and do not differ in their ability to bind to DNA in a sequence-specific manner. However, there are a number of differences between these p53 variants in their abilities to bind components of the transcriptional machinery, to activate transcription, to induce apoptosis, and to repress the transformation of primary cells (Thomas et al., 1999). It has been shown that the codon 72 polymorphism (Arg-Pro polymorphism) of the common tumor suppressor p53 gene contributes to susceptibility to breast cancer. The Arg/Pro heterozygous genotype occurred more frequently in this cancer. The prevalence of the Arg/Pro genotype in breast cancer was higher than that of other genotypes.

In this study, we examined the prevalence of p53 codon 72 polymorphisms in a number of Iranian groups of breast cancer patients and controls. The prevalence of the Arg/Pro genotype in carcinoma cases was statistically different from that of the controls $(75.55 \%$ versus $62 \%)$. Several studies have examined the role of the codon 72 polymorphism in mutation of the p53 gene in cancer. Langerod et al. (2002) identified p53 mutations more commonly in breast cancer from Arg/Arg homozygotes (28.5\%), than among Arg/Pro heterozygotes (21\%) or Pro/Pro homozygotes (4\%). However, no difference in p53 mutation frequency among codon 72 genotypes has been reported in colorectal or bladder cancer (Furihata et al., 2002). Several studies have also suggested that the codon 72 Arg allele is preferentially mutated and retained in Arg/Pro heterozygotes (Tada et al., 2001). These authors have suggested that the codon 72 Arg containing mutants may have a selective growth advantage influencing the ratio of Arg and Pro containing mutants in tumors. Another study also observed the prevalence of homozygosity for the p53 Arg allele and a strong association between the Arg/Arg genotype in breast cancer patients (Buyru et al., 2003). Recently, higher number of arg allele was observed in breast cancer patients when compared to the controls suggesting that the arg allele may be associated with predisposing India women to breast cancer (Suresh et al., 2011).

\section{CONCLUSIONS}

In this study, the heterozygosity for Arg/Pro of p53 codon 72 was associated with breast cancer. Heterozygosity for Arg/Pro of p53 Arg72Pro is potentially one of the genetic risk factors for breast cancer in Iranian population. Therefore, the p53 Arg72Pro polymorphism may be used as a stratification marker in screening individuals at a high risk of breast cancer. In summary, the findings of the present study indicate that the p53 codon 72 polymorphism may be a genetic predisposing factor for breast adenocarcinomas, and p53 Arg 72 protein may be correlated with possible increased risk of this kind of cancers in central part of Iran.

\section{ACKNOWLEDGEMENT}

The authors are grateful to the competitors of Biotechnology Research Center of Islamic Azad University, Shahrekord Branch, for valuable discussion and useful suggestions of this work.

\section{REFERENCES}

Agorastos T, Masouridou S, Lambropoulos AF, Chrisafi S, Miliaras D, Pantazis K, Constantinides TC, Kotsis A, Bontis I (2004). P53 codon 72 polymorphism and correlation with ovarian and endometrial cancer in Greek women. Eur. J. Cancer Prev. 13:277-280.

Aoki MN, Herrera AC, Amarante MK, Laino do Val Carneiro J, Pelegrinelli Fungaro MH, Ehara Watanabe MA (2009). CCR5 and p53 codon 72 gene polymorphisms: Implications in breast cancer development. Int. J. Mol. Med. 23:429-435.

Buyru N, Tigli H, Dalay N (2003). P53 codon 72 polymorphism in breast cancer. Oncol. Rep., 10(3):711-714.

Chen RH, Chang CT, Wang TY, Huang WL, Tsai CH, Tsai FJ (2008). p53 Codon 72 Proline/Arginine Polymorphism and Autoimmune Thyroid Diseases, J. Clin. Lab. Anal. 22:321-326.

Doosti A, Ghasemi Dehkordi P, Davoudi N (2011). A p53 codon 72 polymorphism associated with breast cancer in Iranian patients. Afr. J. Pharm. Pharmacol. 5:1278-1281.

Furihata $M$, Takeuchi $T$, Matsumoto $M$, Kurabayashi $A$, Ohtsuki $Y$, Terao N, Kuwahara M, Shuin T (2002). p53 mutation arising in Arg72 allele in the tumorigenesis and development of carcinoma of the urinary tract. Clin. Cancer Res. 8:192-1195.

He XF, Su J, Zhang Y, Huang X, Liu Y, Ding DP, Wang W, Arparkorn K (2011). Association between the p53 polymorphisms and breast cancer risk: meta-analysis based on case-control study. Breast 
Cancer Res. Treat. In press.

Jiang P, Liu J, Li W, Zeng X, Tang J (2010). Role of p53 and p21 polymorphisms in the risk of cervical cancer among Chinese women. Acta Biochim. Biophys. Sin. 42:671-676.

Langerod A, Bukholm I, Bregard A, Lønning PE, Andersen TI, Rognum TO, Meling GI, Lothe RA, Børresen-Dale AL (2002). The TP53 codon 72 polymorphism may affect the function of TP53 mutations in breast carcinomas but not in colorectal carcinomas. Cancer Epidemiol. Biomarkers Prev. 11:1684-1688.

Mabrouk I, Baccouche S, El-Abed R, Mokdad-Gargouri R, Mosbah A, Said S, Daoud J, Frikha M, Jlidi R, Gargouri A (2003). No evidence of correlation between p53 codon 72 polymorphism and risk of bladder or breast carcinoma in Tunisian patients. Ann. NY Acad. Sci. 10: 764-770.

Omori S, Yoshida S, Kennedy S, Negoro K, Hamana S, Barlow D, Maruo T (2004). Polymorphism at codon 72 of the p53 gene is not associated with endometriosis in a Japanese population. Gynecol. Investing 11: 232-236.

Özbey U, Yüce H, Namli M, Elkiran T (2011). Investigation of Differences in P53 Gene Polymorphisms between Schizophrenia and Lung Cancer Patients in the Turkish Population. Genet. Res. Int. pp. $1-9$.

Pich A, Margarin E, Chiusa L (2000). Oncogenes and male breast carcinoma: c-erbB-2 and p53 coexpression predicts a poor survival. J. Clin. Oncol. 18:2948-2956.

Suresh K, Venkatesan R, Chandirasekar R, Kumar BL, Sasikala K (2011). Association of Trp53 arg72pro polymorphic variants with breast cancer - a case control study in south Indian population. Biol. Med. 3: 15-22.
Tada M, Furuuchi K, Kaneda M, Matsumoto J, Takahashi M, Hirai A, Mitsumoto $\mathrm{Y}$, Iggo RD, Moriuchi T (2001). Inactivate the remaining p53 allele or the alternate p73? Preferential selection of the Arg72 polymorphism in cancers with recessive p53 mutants but not transdominant mutants. Carcinogenesis 22:515-517.

Takeda A, Shimada H, Nakajima K, Suzuki T, Hori S, Hayashi H (2000). Impact of circulating p53 autoantibody monitoring after endoscopic resection in mucosal gastric cancer. Endoscopy 32:740-741.

Thomas M, Kalita A, Labrecque S, Pim D, Banks L, Matlashewski G (1999). Two polymorphic variants of wild-type p53 differ biochemically and biologically. Mol. Cell Biol. 19:1092-1100.

Zubo P, Stanclova A, Kajo K, Hato J, Klobusiakov K, Visnovsk J, Danko $\mathrm{J}$ (2009). The p53 Codon 72 Exon 4 BstU I Polymorphism and Endometrial Cancer in Caucasian Women. Clin. Trans. Res. 76: 173-183.

Zur Hausen H (2002). Papillomaviruses and cancer: from basic studies to clinical application. Nat. Rev. Cancer. 2:342-350. 